\title{
Association of eating out with bone density in Taiwan
}

\author{
Yu-Hung Huang ${ }^{1,2}$, Chao-Cheng Lin ${ }^{3}$, Ching-l Lin ${ }^{4}$ and Shyh-Hsiang Lin ${ }^{1, *}$ \\ ${ }^{1}$ School of Nutrition and Health Sciences, Taipei Medical University, 110 Taipei, Taiwan, Republic of China: \\ ${ }^{2}$ Department of Family Medicine, Taipei Medical University Hospital, Taipei, Taiwan, Republic of China: \\ ${ }^{3}$ International Integrated Systems, Inc., New Taipei City, Taiwan, Republic of China: ${ }^{4}$ Department of Nutrition and \\ Health Sciences, Kainan University, Taoyuan, Taiwan, Republic of China
}

Submitted 8 November 2016: Final revision received 22 May 2017: Accepted 26 June 2017: First published online 29 August 2017

\begin{abstract}
Objective: The present study analysed data derived from the 2004-2008 Nutrition and Health Survey in Taiwan, conducted by the Ministry of Health and Welfare, to understand the relationship among eating-out behaviour, related non-nutritional factors and osteopenia in the Taiwanese population.

Design/Setting/Subjects: Data of 1140 adults who had been evaluated with dualenergy X-ray absorptiometry in June 2007 were included. The data were analysed through descriptive and inferential statistics to determine the association of osteopenia with the frequency of eating out, demographic variables (i.e. age, sex, level of education, marital status and place of birth), BMI, waist circumference and food consumption.

Results: Gender, age, education level, personal income and waist circumference were all factors found to be significantly associated with eating-out frequency and the incidence of osteopenia. Eating-out frequency was negatively associated with the incidence of osteopenia. Individuals with BMI $>27 \mathrm{~kg} / \mathrm{m}^{2}$ had a lower frequency of eating out and a lower incidence of osteopenia. Individuals with a lower monthly income had a significantly greater chance of developing osteopenia. Men living without spouses had significantly higher chances of osteopenia. Ca intake was negatively associated with breakfast eating-out frequency.

Conclusions: Eating-out frequency was not associated with an increasing incidence of osteopenia, but affected the Ca intake in the Taiwanese population. Having a balanced selection of food is crucial to reduce the incidence of osteopenia. Improving nutritional knowledge for those under higher risk of osteopenia is necessary to prevent osteopenia and Ca deficiency.
\end{abstract}

Keywords
Eating out
Osteopenia
Calcium
Dual-energy X-ray absorptiometry
BMI

The loss of postmenopausal bone mass depends largely on chronological age and time since the onset of menopause ${ }^{(10)}$. The effect of body weight on bone is two-sided. Obesity is likely to adversely affect bone health ${ }^{(11,12)}$. Moreover, underweight people tend to be easily susceptible to osteopenia ${ }^{(13)}$. A positive association exists between BMI and bone mineral density ${ }^{(14)}$.

Eating out frequently leads to insufficient dietary intake of nutrients such as $\mathrm{Ca}^{(15)}$. Because of rapid economic development and structural changes in the traditional diet in Taiwan ${ }^{(16)}$, the frequency with which modern nationals eat out is increasing. A 1996 survey revealed that 48 and $34 \%$ of Taiwanese citizens eat out at lunchtime on weekdays and weekends, respectively ${ }^{(17)}$. Ca is the major component of bones ${ }^{(18)}$. The typical Western diet consists of milk, cheese and bread, whereas rice is the primary component of a typical Eastern meal ${ }^{(19)}$, and when Taiwanese people eat out, rice and starch-based foods remain the mainstay. No study has yet analysed Taiwanese 
citizens for their eating-out behaviour. Using a database derived from the 2004-2008 Nutrition and Health Survey in Taiwan (NAHSIT) ${ }^{(20)}$, the present study investigated the relationship among eating-out behaviour, related non-nutritional factors and incidence of osteopenia in Taiwanese nationals.

\section{Materials and methods}

\section{Data sampling}

The present study employed a cross-sectional research design and performed secondary data analyses. Data were collected from the 2004-2008 NAHSIT database mentioned above. First, data of 3670 individuals, including 862 children and 2808 adults, were drawn from the original databank, of which the data of 1140 ( 567 men and 573 women) adults who had been evaluated with dual-energy X-ray absorptiometry (Lunar Prodigy instrument; GE Healthcare, Milwaukee, WI, USA) were included. The data were analysed through descriptive and inferential statistics to determine the association of osteopenia with the frequency of eating out, demographic variables (i.e. age, sex, level of education, marital status and place of birth), BMI, waist circumference and food consumption. Using $24 \mathrm{~h}$ dietary recalls and dietary records and questionnaire data as the research foundation, the present study retrieved the test data of individuals who underwent dual-energy X-ray absorptiometry examinations for measurement of bone mineral density. We used the 2003 WHO criteria to classify bone mineral density as osteoporosis ( $T$-score $\leq-2 \cdot 5)$, osteopenia ( $T$-score $=-2.5$ to $1 \cdot 0)$ or normal ( $T$-score $\geq-1 \cdot 0)$. Twenty of the study participants were diagnosed with osteopenia. Both osteoporosis and osteopenia $(T$-score $<-1 \cdot 0)$ were collectively treated as the dependent variable, and the independent variables were the main meal type (breakfast, lunch or dinner), eating-out frequency per week (not more than six times weekly was termed 'infrequent' and more than seven times weekly was termed 'frequent'), age ( $<40$ years and $>50$ years; ages between 40 and 50 years were omitted due to the transition of menopausal period for females), sex, level of education, marital status, BMI (as defined by the Ministry of Health and Welfare, Taiwan; BMI $<18.5 \mathrm{~kg} / \mathrm{m}^{2}$ was categorized as underweight, BMI $=18.5-24.0 \mathrm{~kg} / \mathrm{m}^{2}$ as normal, $\mathrm{BMI}=24 \cdot 0-27 \cdot 0 \mathrm{~kg} / \mathrm{m}^{2}$ as overweight and BMI $>27.0 \mathrm{~kg} / \mathrm{m}^{2}$ as obese), waist circumference (men and women with waist circumference $\geq 90 \mathrm{~cm}$ and $\geq 80 \mathrm{~cm}$, respectively, were defined as obese $\left.{ }^{(21)}\right)$, individual monthly income and place of birth. The differences in the definition of underweight, normal, overweight and obese between Asian and Caucasian populations are due to the interaction of race and dietary patterns ${ }^{(22-24)}$.

\section{Statistical analyses}

Statistical analyses were conducted using the statistical software package SPSS for Windows version 16.0. The $\chi^{2}$ test,
Fisher's exact test, Mann-Whitney $U$ test, multiple regression analysis and the Kruskal-Wallis $H$ test were conducted with the level of significance set at $P<0.05$.

\section{Results}

In total, 567 men (49.7\%) and 573 women (50.3\%) with a mean age of 52.43 years participated in the dual-energy $\mathrm{X}$-ray absorptiometry examination. Linear correlation analyses indicated that the relationships between the frequency of eating out and demographic variables, namely sex, age, marital status, level of education, personal income and waist circumference, were significant $(P<0 \cdot 001$, Table 1). The frequency of eating out was significantly higher in men than in women $(P<0 \cdot 001)$. Moreover, single and young participants and those with a higher education level or personal income ate out more frequently than did their corresponding counterparts. Age-based analyses revealed a decreasing eating-out trend with increasing age. We also observed that BMI $(r=-0.75, P=0.014)$ and female waist circumference $(r=-0 \cdot 19, P<0 \cdot 001)$ were significantly negatively correlated

Table 1 Demographic variables and eating-out frequency among Taiwanese adults, 2004-2008 Nutrition and Health Survey in Taiwan

\begin{tabular}{|c|c|c|c|c|}
\hline \multirow[b]{2}{*}{ Demographic variable } & \multirow[b]{2}{*}{$n$} & \multicolumn{2}{|c|}{$\begin{array}{l}\text { Frequency of } \\
\text { eating out } \\
\text { (meals/week) }\end{array}$} & \multirow[b]{2}{*}{$P$} \\
\hline & & Mean & SD & \\
\hline Sex & & & & $<0.001^{*}$ \\
\hline Male & 524 & 6.82 & $6 \cdot 29$ & \\
\hline Female & 536 & 4.88 & 5.79 & \\
\hline Age (years) & & & & $<0.001 \dagger$ \\
\hline $20-29$ & 151 & 9.87 & $6 \cdot 12$ & \\
\hline $30-39$ & 109 & $9 \cdot 67$ & $6 \cdot 15$ & \\
\hline $40-49$ & 184 & $7 \cdot 66$ & $6 \cdot 10$ & \\
\hline $50-59$ & 217 & $5 \cdot 62$ & 5.67 & \\
\hline $60-69$ & 175 & $2 \cdot 86$ & 4.22 & \\
\hline Marital status & & & & $<0.001 \dagger$ \\
\hline Never & 149 & 9.03 & $6 \cdot 29$ & \\
\hline Married & 765 & $5 \cdot 67$ & 5.98 & \\
\hline Divorce & 20 & 7.34 & 7.78 & \\
\hline Separated & 3 & 5.83 & 8.84 & \\
\hline Widowed & 116 & $2 \cdot 70$ & 4.39 & \\
\hline Level of education & & & & $<0.001 \dagger$ \\
\hline Primary school & 352 & $2 \cdot 82$ & 4.47 & \\
\hline Junior & 125 & $6 \cdot 11$ & 6.69 & \\
\hline High school & 294 & 6.93 & $6 \cdot 11$ & \\
\hline College & 251 & 8.44 & 6.09 & \\
\hline Graduate school & 28 & $9 \cdot 11$ & 6.44 & \\
\hline Others & 9 & $2 \cdot 78$ & 3.28 & \\
\hline Personal income (NTD/month) & & & & $<0.001 \dagger$ \\
\hline$\leq 20000$ & 589 & 3.85 & 5.09 & \\
\hline $20000-60000$ & 328 & 9.03 & $6 \cdot 48$ & \\
\hline$>60000$ & 69 & 7.99 & 5.40 & \\
\hline Waist circumference & & & & $<0.001^{*}$ \\
\hline Normal & 632 & 6.55 & $6 \cdot 31$ & \\
\hline Obese & 424 & 4.80 & $5 \cdot 66$ & \\
\hline
\end{tabular}

NTD, new Taiwan dollars.

*Mann-Whitney $U$ test.

†Kruskal-Wallis $H$ test.

$\ddagger$ Waist circumference $<90 \mathrm{~cm}$ in men and $<80 \mathrm{~cm}$ in women were used as the cut-off levels for central obesity. 
Table 2 Relationships between osteopenia* and demographic variables among Taiwanese adults, 2004-2008 Nutrition and Health Survey in Taiwan

\begin{tabular}{|c|c|c|c|}
\hline \multirow[b]{2}{*}{ Demographic variable } & \multicolumn{2}{|c|}{ Cases of osteopenia } & \multirow[b]{2}{*}{$P+$} \\
\hline & $n$ & $\%$ & \\
\hline Sex & & & $<0.001$ \\
\hline Male & 63 & $11 \cdot 2$ & \\
\hline Female & 182 & $32 \cdot 0$ & \\
\hline BMI & & & 0.001 \\
\hline Underweight & 15 & 48.4 & \\
\hline Normal & 106 & $21 \cdot 7$ & \\
\hline Overweight & 120 & $19 \cdot 8$ & \\
\hline Waist circumference & & & 0.008 \\
\hline Normal & 127 & $19 \cdot 0$ & \\
\hline Obese & 115 & $25 \cdot 2$ & \\
\hline Effective sunlightł & & & 0.513 \\
\hline Yes & 57 & $20 \cdot 8$ & \\
\hline No & 163 & $21 \cdot 0$ & \\
\hline Personal income (NTD/month) & & & $<0.001$ \\
\hline$<20000$ & 186 & $29 \cdot 3$ & \\
\hline$>20000$ & 51 & $12 \cdot 2$ & \\
\hline Level of education & & & $<0.001$ \\
\hline Senior high school and lower & 205 & 24.7 & \\
\hline College and higher & 33 & 11.4 & \\
\hline Age stratified (years) & & & $<0.001$ \\
\hline$<40$ & 26 & 5.4 & \\
\hline$>50$ & 219 & $33 \cdot 6$ & \\
\hline
\end{tabular}

NTD, new Taiwan dollars.

*Osteopenia is when bone mineral density $T$-score is $<-1.0$.

†Fisher's exact test.

¥Slight redness of the skin from sunlight, at least two or three times weekly.

with eating-out frequency, while male waist circumference was not significantly correlated with eating-out frequency. As shown in Table 2, sex, BMI, waist circumference, personal income, level of education and age were all significant factors $(P<0.05)$ affecting the incidence of osteopenia. Effective sunlight (slight redness of the skin from sunlight, at least two or three times weekly) ${ }^{(25)}$ was not a significant factor. Despite the reverse correlation between age and eating-out frequency, no significant difference in Ca intake across ages was observed (data not shown). Individuals with osteopenia ate out significantly less frequently ( 5.4 meals/week) than did those without osteopenia (6.1 meals/week, $P=0 \cdot 001)$. In addition, we found that males, over 50 years old, with a monthly income lower than NTD 20000 had a significantly lower Ca intake $(594.3 \mathrm{mg} / \mathrm{d})$ compared with those $(719.2 \mathrm{mg} / \mathrm{d})$ whose was greater than NTD $20000(P=0 \cdot 012)$.

Table 3 shows that for those with normal BMI, the incidence rate of osteopenia was $34.6 \%$, which is significantly higher $(P=0.045)$ than for those with $\mathrm{BMI}>27 \mathrm{~kg} / \mathrm{m}^{2}$ (26.2\%); individuals older than 50 years with $\mathrm{BMI}>27 \mathrm{~kg} / \mathrm{m}^{2}$ had a lower percentage of osteopenia compared with their counterparts with normal BMI ( 40.8 v. $52.7 \%, P=0.057$ for women; 5.7 v. $18.5 \%$, $P=0.009$ for men). Females aged less than 40 years exhibited a similar trend $(0.0 \quad v .8 .2 \%, P=0.037)$. In addition, as shown in Table 4 , bone mineral density $T$-scores in men without a spouse were significantly lower
Table 3 Osteopenia incidence according BMI (normal and obese ${ }^{\star}$ ), sex and age among Taiwanese adults, 2004-2008 Nutrition and Health Survey in Taiwan

\begin{tabular}{|c|c|c|c|c|c|}
\hline \multirow[b]{2}{*}{ Group } & \multirow[b]{2}{*}{ BMI } & & \multicolumn{2}{|c|}{ Osteopenia } & \multirow[b]{2}{*}{$P \dagger$} \\
\hline & & & No & Yes & \\
\hline Pooled & $\begin{array}{l}\text { Normal } \\
>27 \mathrm{~kg} / \mathrm{m}^{2}\end{array}$ & $\begin{array}{l}n \\
\% \\
n \\
\%\end{array}$ & $\begin{array}{c}153 \\
65 \cdot 4 \\
124 \\
73 \cdot 8\end{array}$ & $\begin{array}{l}81 \\
34 \cdot 6 \\
44 \\
26 \cdot 2\end{array}$ & 0.045 \\
\hline Women aged $<40$ years & $\begin{array}{l}\text { Normal } \\
>27 \mathrm{~kg} / \mathrm{m}^{2}\end{array}$ & $\begin{array}{l}n \\
\% \\
n \\
\%\end{array}$ & $\begin{array}{c}123 \\
91 \cdot 8 \\
45 \\
100 \cdot 0\end{array}$ & $\begin{array}{c}11 \\
8 \cdot 2 \\
0 \\
0\end{array}$ & 0.037 \\
\hline Men aged $<40$ years & $\begin{array}{l}\text { Normal } \\
>27 \mathrm{~kg} / \mathrm{m}^{2}\end{array}$ & $\begin{array}{l}n \\
\% \\
n \\
\%\end{array}$ & $\begin{array}{l}100 \\
93 \cdot 5 \\
45 \\
93 \cdot 8\end{array}$ & $\begin{array}{c}7 \\
6 \cdot 5 \\
3 \\
6 \cdot 2\end{array}$ & 0.626 \\
\hline Women aged $>50$ years & $\begin{array}{l}\text { Normal } \\
>27 \mathrm{~kg} / \mathrm{m}^{2}\end{array}$ & $\begin{array}{l}n \\
\% \\
n \\
\%\end{array}$ & $\begin{array}{l}52 \\
47 \cdot 3 \\
58 \\
59 \cdot 2\end{array}$ & $\begin{array}{l}58 \\
52 \cdot 7 \\
40 \\
40 \cdot 8\end{array}$ & 0.057 \\
\hline Men aged $>50$ years & $\begin{array}{l}\text { Normal } \\
>27 \mathrm{~kg} / \mathrm{m}^{2}\end{array}$ & $\begin{array}{l}n \\
\% \\
n \\
\%\end{array}$ & $\begin{array}{l}101 \\
81 \cdot 5 \\
66 \\
94 \cdot 3\end{array}$ & $\begin{array}{l}23 \\
18 \cdot 5 \\
4 \\
5 \cdot 7\end{array}$ & 0.009 \\
\hline
\end{tabular}

${ }^{*}$ Normal, BMI $=18.5-24.0 \mathrm{~kg} / \mathrm{m}^{2}$; obese, BMI $>27.0 \mathrm{~kg} / \mathrm{m}^{2}$.

$\dagger \%$ Normal $v$. \% obese by Mann-Whitney $U$ test.

Table 4 Relationship of marital status and bone mineral density according to age and sex among Taiwanese adults, 2004-2008 Nutrition and Health Survey in Taiwan

\begin{tabular}{llcrrr}
\hline & & & \multicolumn{3}{c}{ Average } \\
Age group & Sex & Marital status* $^{*} n$ & $T$-score & $P \dagger$ \\
\hline$<40$ years & Men & Yes & 169 & 0.1849 & 0.002 \\
& & No & 79 & -0.1273 & \\
& \multirow{2}{*}{ Women } & Yes & 141 & 0.4425 & 0.665 \\
& & No & 86 & 0.4954 & \\
$>50$ years & Men & Yes & 218 & -0.8679 & $<0.001$ \\
& \multirow{2}{*}{ Women } & No & 100 & -1.4079 & \\
& & Yes & 281 & 0.1536 & 0.048 \\
& & No & 49 & -0.1793 & \\
\hline
\end{tabular}

*Includes married and cohabitating couples.

†Yes $v$. no by Mann-Whitney $U$ test.

than those of men with a spouse for those aged both under 40 years and over 50 years. The association between eating-out frequency of the major daily meals and $\mathrm{Ca}$ intake in Taiwanese is shown in Table 5. The eating-out frequency of breakfast, especially in men, was significantly negatively associated with the daily Ca intake $(P=0.006)$.

\section{Discussion}

At the beginning of the present investigation, BMI of $24 \mathrm{~kg} / \mathrm{m}^{2}$ was used as the overweight cut-off point. However, the outcome was susceptible to potential interference by nonobese participants when analysing the relationships of obesity (using waist circumference and BMI values) with 
Table 5 Relationship between eating-out frequency of the major daily meals and calcium intake, overall and according to sex, among Taiwanese adults, 2004-2008 Nutrition and Health Survey in Taiwan

\begin{tabular}{llrr}
\hline Group & Eating-out meal & \multicolumn{1}{c}{$\beta$} & $P^{*}$ \\
\hline All & Breakfast & -12.853 & 0.016 \\
& Lunch & 1.014 & 0.875 \\
Sex & Dinner & -8.155 & 0.328 \\
Male & & & \\
& Breakfast & -19.501 & 0.006 \\
& Lunch & 8.576 & 0.288 \\
Female & Dinner & -13.520 & 0.199 \\
& Breakfast & -7.744 & 0.339 \\
& Lunch & -15.767 & 0.136 \\
& Dinner & 2.290 & 0.863 \\
\hline
\end{tabular}

${ }^{*}$ Multiple regression analysis.

weekly frequency of eating out and bone density. Therefore, the decision was made to adopt targeted sampling; we therefore selected 483 participants with $\mathrm{BMI}<27 \mathrm{~kg} / \mathrm{m}^{2}$ (42.5\%) and 262 participants with BMI $>27 \mathrm{~kg} / \mathrm{m}^{2}(23.1 \%)$ for analysis and comparison. Being overweight (BMI $>24$ $\mathrm{kg} / \mathrm{m}^{2}$ ) and high bone density have been found to be correlated. In addition, a reduction in body weight can lead to osteopenia ${ }^{(26-28)}$. The present study demonstrated that participants with excessive waist circumference were less susceptible to osteopenia and a well-established statistical correlation exists between these two factors.

The average age of menopause onset in females is 51 years ${ }^{(29)}$. In the present study, we did not include the ages between 40 and 50 years due to consideration of the transitional period of menopause in women, to minimize the age bias when some of the females had not yet been through the menopausal period. In our study we found that among women aged under 40 years and men aged over 50 years, the incidence rate of osteopenia in participants with obesity was significantly lower than that in participants with normal weight. Regardless of statistical significance, the incidence rate of osteopenia in obese participants across all strata was lower than that in participants with normal weight. Both obesity and osteoporosis are complex diseases and typically exhibit multifactorial aetiologies that are influenced by hereditary and environmental factors ${ }^{(30)}$.

We found that the people with lower incomes had lower daily $\mathrm{Ca}$ intake and were more susceptible to osteopenia than were those with higher incomes, and they ate out less frequently than did those with higher incomes, suggesting that those with a higher socio-economic status are capable of eating out more frequently and have access to a wider range of food choices compared with those with a lower socio-economic status, which agrees with the assumption that people who frequently eat out typically have a higher socio-economic background ${ }^{(31)}$. In Taiwan, the major dietary $\mathrm{Ca}$ sources are vegetables, soya-, egg- and milk-containing foods, and fish products ${ }^{(32)}$. The fact that the $\mathrm{Ca}$ in vegetables and soya is not absorbed and utilized as efficiently as that from animal sources may be one of the reasons for the inefficient intake of $\mathrm{Ca}$ in Taiwan. We also found that single or divorced men may have an increased risk of osteopenia, which may be due to their imbalanced selection of food. It has been indicated that married men and women tend to follow dietary guidelines and are more balanced in their food selection ${ }^{(33)}$. In addition to Ca intake, bone density may also be affected by other factors such as the intake of vitamin D, the time of exposure to effective sunlight, and even the protein quality of food ${ }^{(34-36)}$ since higher intakes of $\mathrm{Ca}$ (greater than $1100 \mathrm{mg} / \mathrm{d}$ ) did not guarantee higher $T$-scores in the present study.

Although we have made a great effort to exclude some interfering variables that may have affected our conclusions, some limitations in the study still need to be addressed. First, due to the cross-sectional nature of the study, we can only find the associations at a point in time, and not cause-and-effect correlations. Second, due to the content of the questionnaires, we were not able to provide more details on the foods consumed more frequently when eating out compared with when eating at home. Third, although we excluded the data of females aged 40-50 years, there were still some possibilities that some of the females included had an early or a late menopausal condition, which can be one of the confounding variables.

\section{Conclusion}

In conclusion, in the current cross-sectional study, eatingout frequency affected $\mathrm{Ca}$ intake but was not associated with increasing the incidence of osteopenia in the Taiwanese population since $\mathrm{Ca}$ intake is not the only factor affecting bone density. Having a balanced selection of food is crucial to reduce the incidence of osteopenia. Improving nutritional knowledge for those with a higher risk of osteopenia is necessary to prevent osteopenia and Ca deficiency.

\section{Acknowledgements}

Financial support: This research received no specific grant from any funding agency in the public, commercial or notfor-profit sectors. Conflict of interest: Y.-H.H., C.-C.L., C.-I.L. and S.-H.L. declare that they have no competing financial interests and no conflicts of interest. Authorship: Y.-H.H. performed the data collection and analysis. C.-C.L. also performed the data analysis. C.-I.L. was involved in the discussion of results and commented on the manuscript. S.-H.L. conducted the study, interpreted the data, and completed the manuscript. Ethics of human subject participation: This article complies with ethical standards, and the data were used under the approval of Survey Research Data Archive of Academia Sinica, Taiwan. 


\section{References}

1. Lin WY (2002) Family changes and family policy in Taiwan. J NTU Soc Work 6, 35-88.

2. Wang H-H \& Tsay S-F (2012) Elderly and long-term care trends and policy in Taiwan: challenges and opportunities for health care professionals. Kaohsiung J Med Sci 28, 465-469.

3. Ministry of Health and Welfare (2010) Ministry of Health and Welfare. http://www.mohw.gov.tw/cht/DOS/Statistic.aspx? f_list_no=312 (accessed August 2016).

4. Hanson GH (2010) The governance of migration policy. J Hum Dev Capabil 11, 185-207.

5. Ministry of the Interior, Department of Household Registration (2011) Ministry of the Interior. http://www.sowf.moi. gov.tw/stat/week/list.htm (accessed August 2016).

6. Directorate-General of Budget (2010) Population estimate calculation in Taiwan 2010-2060. http://eng.dgbas.gov.tw/ lp.asp?CtNode $=2351 \&$ CtUnit $=1072 \&$ BaseDSD $=36$ (accessed August 2016).

7. Chie W, Yang R, Liu J et al. (2004) High incidence rate of hip fracture in Taiwan: estimated from a nationwide health insurance database. Osteoporos Int 15, 998-1002.

8. Gallagher J, Riggs B \& Eisman J (1994) Diagnosis, prophylaxis, and treatment of osteoporosis. Am J Med 90, 646-650.

9. Nordin B, MacGregor J \& Smith D (1966) The incidence of osteoporosis in normal women: its relation to age and menopause. QJM 35, 25-38.

10. Rico H, Revilla M, Villa L et al. (1993) Age-related differences in total and regional bone mass: a cross-sectional study with DXA in 429 normal women. Osteoporos Int 3, 154-159.

11. Beresford J, Bennett J, Devlin C et al. (1992) Evidence for an inverse relationship between the differentiation of adipocytic and osteogenic cells in rat marrow stromal cell cultures. J Cell Sci 102, 341-351.

12. Cao JJ (2011) Effects of obesity on bone metabolism. J Orthop Surg Res 6, 30-36.

13. Szklarska A \& Lipowicz A (2012) BMI, hypertension and low bone mineral density in adult men and women. Homo $\mathbf{6 3}$, 282-291.

14. Dytfeld J, Ignaszak-Szczepaniak M, Gowin E et al. (2011) Influence of lean and fat mass on bone mineral density (BMD) in postmenopausal women with osteoporosis. Arch Gerontol Geriatr 53, e237-e242.

15. Zhai F, Wang H, Du S et al. (2007) Lifespan nutrition and changing socio-economic conditions in China. Asia Pac J Clin Nutr 16, 374-382.

16. Chen TS (2010) The study of the determinant on food-awayfrom-home expenditure-an application of cohort analysis. J Chaoyang Univ Technol 15, 45-68.

17. Li C (2006) A study of relationships between restaurant consumer purchase involvement and purchase decision. Master's Thesis, Ming Chuan University.

18. Vallet-Regi M \& González-Calbet JM (2004) Calcium phosphates as substitution of bone tissues. Prog Solid State Chem 32, $1-31$.
19. Yang S-S \& Zhang Y-X (2010) The research of the differences between Chinese and Western diet cultures. Cross-Cult Commun 6, 75-83.

20. Research Center for Humanities and Social Sciences Academia Sinica. (2011) 2004-2008 Nutrition and Health Survey in Taiwan (NAHSIT). https://srda.sinica.edu.tw/ group/sciitem/3/1302 (accessed September 2012).

21. Ministry of Health and Welfare (2016) BMI measurement. http://www.health99.hpa.gov.tw/en/ (accessed August 2016).

22. Pan Y-L, Dixon Z, Himburg S et al. (1999) Asian students change their eating patterns after living in the United States. J Am Diet Assoc 99, 54-57.

23. Romero-Gwynn E, Gwynn D, Grivetti L et al. (1993) Dietary acculturation among Latinos of Mexican descent. Nutr Today 28, 6-12.

24. Lee S-K, Sobal J \& Frongillo EA (1999) Acculturation and dietary practices among Korean Americans. J Am Diet Assoc 99, 1084-1089.

25. Güler T, Sivas F, Başkan BM et al. (2007) The effect of outfitting style on bone mineral density. Rheumatol Int $\mathbf{2 7}$, 723-727.

26. Wardlaw GM (1996) Putting body weight and osteoporosis into perspective. Am J Clin Nutr $\mathbf{6 3}, 3$ Suppl, 433S-436S.

27. Guney E, Kisakol G, Ozgen G et al. (2003) Effect of weight loss on bone metabolism: comparison of vertical banded gastroplasty and medical intervention. Obes Surg 13, 383-388.

28. Radak TL (2004) Caloric restriction and calcium's effect on bone metabolism and body composition in overweight and obese premenopausal women. Nutr Rev 62, 468-481.

29. Daan NM \& Fauser BC (2015) Menopause prediction and potential implications. Maturitas 82, 257-265.

30. Zhao L-J, Liu Y-J, Liu P-Y et al. (2007) Relationship of obesity with osteoporosis. J Clin Endocrinol Metabol 92, 1640-1646.

31. Lachat C, Nago E, Verstraeten R et al. (2012) Eating out of home and its association with dietary intake: a systematic review of the evidence. Obes Rev 13, 329-346.

32. Wu S-J, Chang Y-H, Chang H-Y et al. (2001) Food sources of dietary calcium, phosphorus, iron, and sodium: Nutrition and Health Survey in Taiwan (NAHSIT) 1993-1996. Nutr Sci J 26, 142-158.

33. Roos E, Lahelma E, Virtanen M et al. (1998) Gender, socioeconomic status and family status as determinants of food behaviour. Soc Sci Med 46, 1519-1529.

34. Cauley JA (2017) Osteoporosis: fracture epidemiology update 2016. Curr Opin Rheumatol 29, 150-156.

35. Mangano KM, Sahni S, Kiel DP et al. (2015) Bone mineral density and protein-derived food clusters from the Framingham Offspring Study. I Acad Nutr Diet 115 , 1605-1613.e1.

36. Sahni S, Broe KE, Tucker KL et al. (2014) Association of total protein intake with bone mineral density and bone loss in men and women from the Framingham Offspring Study. Public Health Nutr 17, 2570-2576. 